
About IJMA [last updated July, $\left.1^{\text {st }}, 2021\right]$

$\checkmark$ International Journal of Medical Arts is the Official Journal of the Damietta Faculty of Medicine, AlAzhar University, Egypt

$\checkmark$ It is an International, Open Access, Double-blind, Peer-reviewed Journal

$\checkmark$ Published four times a year

$\checkmark$ The First Issue was published in July 2019

$\checkmark$ Published under the following license: Creative Commons Attribution-ShareAlike 4.0 International Public License (CC BY-SA 4.0). It had updated from the Creative Commons license [CC BY] in volume 2, Issue 4, October 2020 About IJMA

$\checkmark$ The Egyptian Knowledge Bank hosts the web site of IJMA

$\checkmark$ The Egyptian Knowledge Bank supports IJMA

$\checkmark$ IJMA follows the regulations of the International Committee of Medical Journal Editors

$\checkmark$ IJMA is indexed in the "Directory of Open Access Journals" [15 January 2021].

$\checkmark$ IJMA is indexed in JGate [29-6-2021]

$\checkmark$ IJMA is a member of the International Society of Managing and Technical Editors

$\checkmark$ Listed in "Index Copernicus", "Publons", "Academic resource index [ResearchBib]", "Electronics journal library", "Eurasian Scientific Journal Index", and "Citefactor"

$\checkmark$ IJMA introduced to the search engine [BASE] through DOAJ
Click image to reach the page

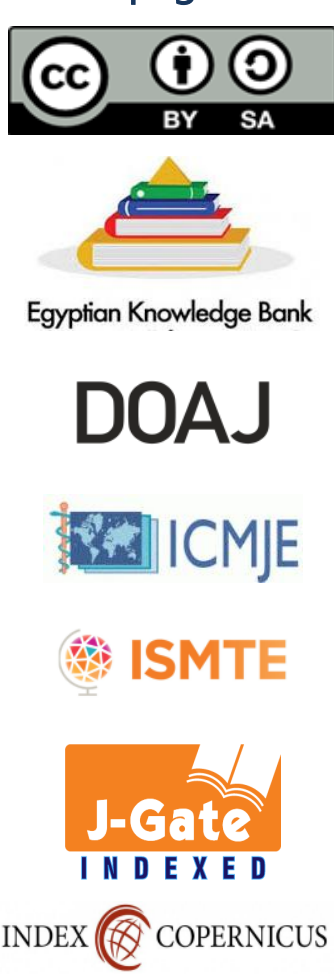

publons

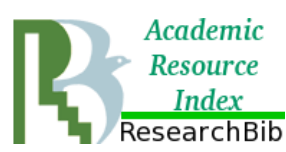

\section{EZ3 \\ .}

ESJII

CiteFactor

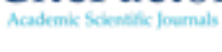

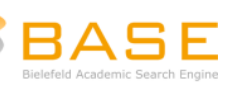




Available online at Journal Website
https:/lijma.journals.ekb.eg/
Main subject [Psychiatry]

Original article

\title{
Perceived Stress and its Contributing Factors among a Group of Egyptian Women during COVID-19 Lockdown.
}

\author{
Hanaa A. Abou Elhassan [1], Heba M. Abd ElGalil [1], Omneya E. Elsherif [2], Safaa Mahmoud Hamouda [3], Omaima M. \\ Aboushady [4], Nadia A. Kotb [5], Amal Saad-Hussien [6] \\ ${ }^{1}$ Department of Community Medicine, Faculty of Medicine for Girls, Al-Azhar University, Egypt. \\ ${ }^{2}$ Department of Family Medicine, Cairo University Hospital, Egypt. \\ ${ }^{3}$ Department of Psychiatry, Faculty of Medicine, Al-Azhar University, Egypt. \\ ${ }^{4}$ Department of Parasitology, Faculty of Medicine, Cairo University, Egypt. \\ ${ }^{5}$ Department of Forensic Medicine and Clinical Toxicology, Faculty of Medicine, Cairo University, Egypt. \\ ${ }^{6}$ Department of Environmental and Occupational Medicine, National Research Centre, Egypt.
}

Corresponding author: Hanaa A. Abou Elhassan.

Email: hanaaabouelyazid@azhar.edu.eg

Submission date: June 13, 2021; Revision date: July 08, 2021; Acceptance date: July 10, 2021.

\section{ABSTRACT}

Background: The pandemic of corona virus disease [COVID]-19 had its great impacts on global health due to the increasing both morbidity and mortality. In addition, being quarantined is linked with high stress levels, insomnia, irritability and trauma-related disorders particularly in vulnerable populations. Therefore, there is a need to assess accurately and timely the magnitude of psychological health outcomes in those having exposure to COVID-19 pandemic.

The Aim: The current work aimed to assess the perceived stress level among a group of Egyptian women and to explore the potential contributing factors for that during the COVID-19 lockdown.

Methods: A cross-sectional survey targeted educated women from different Egyptian governorates, and of different socioeconomic standards. The total sample was 286 women who were recruited by non-probability snowball sampling and through a semi-structured, online questionnaire comprising socio-demographic data, the validated Arabic version of Cohen Perceived Stress Scale 10 [PSS]. Possible contributing factors of the perceived stress due to COVID-19 were also inquired.

Results: total females who responded to the questionnaire were 286 with mean age of $46.5 \pm 11.0$ years. During the quarantine period, the total score of the perceived stress scale was $17.1 \pm 5.37$, and both high and moderate levels of stress were recorded among $73.4 \%$ of the studied sample. Stress level was significantly influenced by disruptions of social communication with friends and families, "getting basic needs for health and safety are unmet then ", conflicts between mother and her children represented as a load", being younger women [below 50 years], and "feel stressed due to inability for social gatherings".

Conclusion: COVID -19 pandemic has its obvious psychological impact on females, and many factors were contributing to such situation, which put the spotlight on the importance of taking these impacts into consideration when designing policies to slow the spread of the pandemic.

Keywords: COVID-19; Perceived Stress; Stress Level; Contributing Factors.

This is an open-access article registered under the Creative Commons, ShareAlike 4.0 International license [CC BY-SA 4.0] [https://creativecommons.org/licenses/by-sa/4.0/legalcode.

Citation: Abou elhassan HA, Abd EIGalil HM, Elsherif OE, Hamouda SM, Aboushady OM, Kotb NA, Saad-Hussien A. "Perceived Stress and its Contributing Factors among a Group of Egyptian Women during COVID-19 Lockdown. IJMA 2021; 3 [3] July-September: 1671-1680. [DOI: 10.21608/IJMA.2021.79373.1322].

${ }^{*}$ Main subject and any subcategories have been classified according to the research topic. 


\section{INTRODUCTION}

Coronavirus pandemic has fundamentally affected worldwide wellbeing [1]. World countries are trying to respond to COVID-19 pandemic, balancing the need to save population lives and slow the spread of infection [2].

Egypt responded progressively to social isolation measures, implementing scientific and balanced tight social gatherings restrictions at different stages during the novel virus spread [3].

Lockdown as a stringent measure to keep people apart caused severe disturbing effect on all society aspects [2]. Pandemic lockdown may lead to psychological health problems due to the increasing both morbidity and mortality; in addition, it may pose a challenge to psychological resilience across different nations. Mental symptoms are influenced by age of the individual, gender, physical activity performed, occupation, specialization, and contact to COVID-19 patients ${ }^{[3]}$.

Furthermore, being quarantined is linked with high stress levels, insomnia, irritability and trauma-related disorders especially in vulnerable populations ${ }^{[4]}$. In a national survey on more than 50,000 Chinese respondents, $35 \%$ of participants experienced symptoms of trauma-related distress, and young adults and women showing significantly greater psychological distress ${ }^{[5]}$.

Stress has a serious impact on one's individual health. Stress Perception is impacted by cultural and socioeconomic factors that vary from one country to another. The prevalence of mental disorders shows the importance of considering stress variables especially in females ${ }^{[6]}$.

Accordingly, there is a need to assess accurately and timely the magnitude of psychological health outcomes in those having exposure to COVID-19 pandemic, with specific respect to the implementation of preventive interventions and social support during the "Stay at Home: lockdown" COVID-19 pandemic social distancing strategy.

\section{AIM OF THE WORK}

The aim of the current research was to assess the level of perceived stress among a group of Egyptian women and to explore the potential contributing factors for that during the lockdown time of COVID-19 pandemic.

\section{METHODS}

Study design: A cross-sectional survey design was carried out during the period from May 1, 2020 to May 15,
2020 , which represents one of the most stressful periods during the early stage of the COVID-19 pandemic in Egypt when lockdown was declared since 24 March 2020. The survey was conducted after obtaining the approval of the ethical committee of National Research Centre [the registered approval number is [M10/2020/055].

Inclusion criteria: Women of 18 years of age and above, educated [secondary educational level and above], from different Egyptian governorates, and of different socioeconomic standards were eligible for the survey. In addition, participants should be able to respond to the online questionnaires. Exclusion criteria were non Egyptian women, and Egyptian women living abroad.

Sample size and sampling technique: As a minimum, we considered that 200 participants would be required to get meaningful result. The upper constrain on the number of participants was not decided to get exact precise estimates of population values and associations, and to be able to divide them into in subgroups. The sample was recruited by a non-probability snowball sampling and through an online questionnaire. The online method of data collection has been found to be an effective way of obtaining valid and reliable data [7].

A well designed questionnaire was uploaded on a Google Form and the link disseminated to 21 e-mail addresses and social media groups and asked them to disseminate the questionnaire link to their acquaintances. A total of 305 returned the questionnaire. Of them, 19 were not fulfilling the inclusion criteria so they have been omitted and the research has been conducted on a total sample of 286 .

The questionnaire began with an invitation message describing the study aim, and the consent form. No payment has been promised for completing the survey and it was anonymous with guaranteed confidentiality of data. The average time for completing the questionnaire was 15 minutes and it lasted online for two weeks.

Ethics approval and consent to participation: All procedures involving human participants in the present study were carried out in compliance with the institutional and/or national research committee's ethical guidelines, as well as the 1964 Helsinki Declaration and its later revisions or equivalent ethical standards. IRB approval was obtained from the Ethical Committee of National Research Centre; [M10/2020/055]. Women volunteered to participate in the study after learning about the goals and giving their consent. Personal information such as name, phone number, and email address were not requested [except on a voluntary basis] in order to protect participants' privacy and information confidentiality. Moreover, participants were 
informed that they can withdraw at any time prior to the completion of the survey. The questionnaire was designed and implemented through medical staff from the Egyptian Medical Women Association [EMWA]. EMWA members represent a group of scholars from different medical backgrounds constituting of Faculties at different Egyptian universities and National Research Centre.

\section{Survey contents and outcome measures:}

The current study was carried out after reviewing the available literature on the emerging COVID-19 pandemic. Participating women were invited to fill a well-designed, semi-structured, online questionnaire including:

1-Socio-demographic data comprising: participant age, residence, education level, marital status, and work status, in addition, her share in family expenses was asked about.

2-The psychological impact of COVID-19: It was measured using the validated Arabic version of Cohen Perceived Stress Scale 10 [PSS] [8]. It is a broadly used psychological tool to measure the degree to how circumstances in one's life are identified as stressful which is perfect for this current circumstances indicated as the pandemic of COVID-19. The Arabic version of PSS 10 was validated [9] and Cronbach's alpha value was 0.836 .

The scale comprised ten items; with a 5-point Likert scale for a final score $[0=$ Never, $1=$ Rarely, $2=$ Sometimes, $3=$ Fairly often, and $4=$ Always]. Items $4,5,7$, and 8 are positively stated and reversely scored [e.g., $0=4,1=3,2=$ $2,3=1$ and $4=0$ ]. Subsequently, the scores were added together to obtain a total score between 0 and 40 with higher scores signifying higher levels of perceived stress.

Stress was classified as follows: Scores ranging from 0 to 13 were considered low-stress level, 14 to 26 as moderate stress, and 27 to 40 as high perceived stress. Both moderate and high stress levels were merged as having stress while Low-stress level considered as having no stress ${ }^{[10]}$.

3-Possible contributing factors of the perceived stress due to COVID-19 occurring in the recent past month. These questions comprising:

a) Changes in family relationship and social life: e.g. getting support from the husband, and from family members [decrease, increase, or the same as before or irrelevant]. Family conflicts due to presence of all family members at home most of the time, and conflicts between the mother and her children, disruptions of social communication with friends and family, feeling of stress due to inability to attend to social gatherings, restriction on going outdoors as a result of lockdown, restriction on recreational outdoor activities, facing financial strain /hardships, getting basic needs for health and safety are unmet and higher workload due to COVID-19. All were inquired about [never/almost never, sometimes, and always] as if it is considered as a stressor. In addition, number of sleeping hours whether decreased, increased or the same as before.

b) COVID-19 infection related factors: Close / indirect contact with a confirmed/ suspected COVID-19 case, getting tested /symptoms or one of her family members for COVID-19. In addition, the fear that the woman /her family contracts COVID-19 due to the nature of the work [yes it put me in stress, no it did not, or not happened with me]. Further we considered the response "yes it put me in stress as a positive response", and "no it did not", or "not happened with me" as a negative response

Data analysis: Data in the Excel calculation matrix were imported into the statistical program SPSS version 16 [SPSS Inc, Chicago, IL, USA] to perform the appropriate data analyses. Quantitative data were described as mean and standard deviation [SD] while qualitative data were expressed in numbers and percentages. Comparison between two means was done by using independent t-test while Chi square-test was used for comparing qualitative data and Fisher's exact test was used instead when more than $20 \%$ of cells have expected frequencies $<5$. Logistic regression analysis was used to explore the influence of the significant variables [tested by univariate analysis] on the PSS level. Significance level was taken at a P-value $<0.05$ and the results were displayed in forms of tables and graphs.

\section{RESULTS}

The current study is an online survey with a total of 305 returned the questionnaire. Of them, 12 responded only to the socio-demographic section or part of it and 7 were not fulfilling the inclusion criteria.

Consequently we omitted those 19 questionnaires and worked on a total sample of 286 .

Table [1] summarizes the socio-demographic data of 286 studied females. Their mean age was $46.5 \pm 11$ ranged between 22 to 68 years, and $42.0 \%$ of them were below 50 
years. The majority [93.7\%] of them were residing urban governorates mainly Cairo [73.8\%], while $12.6 \%, 10.5 \%$, $3.1 \%$ were from Lower Egypt, Frontiers and Upper Egypt respectively.

Most of the females [79.1\%] were married and only $3.9 \%$ of them had living abroad husbands, and the vast majority had a university degree or higher education level [98.3\%]. Regarding working status, about three fourths [74.5\%] were working. In addition, more than two thirds [69.6\%] of them were sharing in family expenses either partially [57.0\%] or completely [12.6\%].

It was found that the mean perceived stress among the studied females was [17.1 \pm 5.37 ] out of 40 , ranged from 4 to 36 ; the study showed that more than two thirds[68.5\%] of females had moderate level of stress, followed by low [26.6\%], then high level of stress [4.9\%] [Table 2].

Table [3] displays the association between sociodemographic characteristics and self-perceived stress. It was found that those who are younger than 50 years of age had significant moderate or high levels of stress [79.5\%] than those who were 50 years and above. Also, working women were significantly having moderate to high level of stress [76.5\%] compared to the non-working ones [64.4\%].

Table [4] showed association between possible stressful factors and PSS level during the epidemic [COVID-19]. A significant association between change in social life and perceived stress as more females who reported moderate or high PSS levels suffered from family conflicts, Conflicts between mother and her children, disruptions of social communication with friends and families, inability for social gatherings, restriction on going outdoors and recreational outdoor activities, facing financial strain /hardship, higher workload due to COVID-19, getting basic needs for health and safety are unmet than their counterparts [those who reported a low PSS levels]. Moreover, decreased sleeping hours was significantly higher among participants with moderate/higher level of stress than those with mild level.

In figures [1a and $b]$ No significant difference has been found between COVID-19 infection related factors and perceived stress level where most of those with positive response suffered from moderate to high PSS level similar to those with negative response $p$ value $[0.7,0.9,0.06$ respectively].

Table [5] demonstrates a logistic regression analysis of significant factors affecting perceived stress level. It was found that disruptions of social communication with friends and families was the strongest factor affecting perceived stress followed by "getting basic needs for health and safety are unmet" then "conflicts between mother and her children represented as a load" followed by being younger women [below 50 years], and "feel stressed due to inability for social gatherings".

Table [1]: Socio-demographic Characteristics of the Studied Females.

\begin{tabular}{|c|c|c|}
\hline \multicolumn{2}{|l|}{ Variable } & \multirow{2}{*}{$\begin{array}{c}\text { Statistical measures } \\
46.5 \pm 11 ; 22-68\end{array}$} \\
\hline Age [years] & mean $\pm S D ;$ mini.-maxi. & \\
\hline \multirow[t]{2}{*}{ Age group } & $>50$ years & $166[58.0 \%]$ \\
\hline & $\leq 50$ years & $120[42.0 \%]$ \\
\hline \multirow[t]{3}{*}{ Residence } & Urban & $268[93.7 \%]$ \\
\hline & Rural & $10[3.5 \%]$ \\
\hline & Suburban & $8[2.8 \%]$ \\
\hline \multirow[t]{2}{*}{ Marital status } & a Married & $226[79.1 \%]$ \\
\hline & ${ }^{\mathrm{b}}$ Not married & $60[20.9 \%]$ \\
\hline \multirow[t]{2}{*}{ Education level } & High school & $5[1.7 \%]$ \\
\hline & University or higher & $281[98.3 \%]$ \\
\hline \multirow[t]{2}{*}{ Work status } & Working & $213[74.5 \%]$ \\
\hline & ${ }^{\mathrm{C}}$ Not working & $73[25.5 \%]$ \\
\hline \multirow[t]{3}{*}{ Sharing in family expenses } & Complete sharing & $36[12.6 \%]$ \\
\hline & Partial sharing & $163[57.0 \%]$ \\
\hline & Not sharing & $87[30.4 \%]$ \\
\hline
\end{tabular}

a $3.9 \%$ had husbands living abroad, ${ }^{b}$ [Widow/Divorced/Separated/Single], ${ }^{c}$ house wife/student/retired.

Table [2]: Distribution of Perceived Stress Level among the Studied Females.

\begin{tabular}{|l|l|c|}
\hline Variable & mean \pm SD; mini.-maxi. & Statistical measures \\
\hline Total stress level & Low & $17.1 \pm 5.37 ; 4-36$ \\
\cline { 2 - 3 } & Moderate & $76[26.6 \%]$ \\
\cline { 2 - 3 } & High & $196[68.5 \%]$ \\
\hline
\end{tabular}


Abou Elhassan HA, et al.

IJMA 2021; 3 [3] July-September: 1671-1680

Table [3]: Distribution of Socio-demographic Characteristics Regarding Level of PSS among the Studied Females

\begin{tabular}{|c|c|c|c|c|}
\hline \multicolumn{2}{|l|}{ Variable } & \multirow{2}{*}{$\frac{\text { Moderate/High [n=210] }}{45.2 \pm 10.8}$} & \multirow{2}{*}{$\frac{\text { Low }[n=76]}{50.1 \pm 10.8}$} & \multirow{2}{*}{$\frac{\mathbf{P}}{0.001^{*}}$} \\
\hline Age [years] & mean $\pm S D$ & & & \\
\hline \multirow[t]{2}{*}{${ }^{* *}$ Age group } & $>50$ years & $132[79.5 \%]$ & $34[20.5 \%]$ & \multirow[t]{2}{*}{$0.006^{*}$} \\
\hline & $\leq 50$ years & $78[65.0 \%]$ & $42[35.0 \%]$ & \\
\hline \multirow[t]{3}{*}{ ** Residence } & Urban & 194 [72.4\%] & $74[27.6 \%]$ & \multirow[t]{3}{*}{0.123} \\
\hline & Rural & $10[100.0 \%]$ & $0[0.0 \%]$ & \\
\hline & Suburban & $6[75.0 \%]$ & $2[25.0 \%]$ & \\
\hline \multirow{2}{*}{${ }^{* *}$ Marital status } & Married & $164[72.6 \%]$ & $62[27.4 \%]$ & \multirow[t]{2}{*}{0.523} \\
\hline & Not married & $46[76.7 \%]$ & $14[23.3 \%]$ & \\
\hline \multirow[t]{2}{*}{${ }^{* *}$ Education level } & University or higher & $206[73.3 \%]$ & $75[26.7 \%]$ & \multirow[t]{2}{*}{1.00} \\
\hline & High school & $4[80.0 \%]$ & $1[20.0 \%]$ & \\
\hline \multirow[t]{2}{*}{${ }^{* *}$ Work status } & Working & $163[76.5 \%]$ & $50[23.5 \%]$ & \multirow[t]{2}{*}{$0.042^{\prime}$} \\
\hline & Not working & $47[64.4 \%]$ & $26[35.6 \%]$ & \\
\hline \multirow[t]{3}{*}{${ }^{* *}$ Sharing in family expenses } & Complete sharing & $23[63.9 \%]$ & $13[36.1 \%]$ & \multirow[t]{3}{*}{0.363} \\
\hline & Partial sharing & $123[75.5 \%]$ & $40[24.5 \%]$ & \\
\hline & Not sharing & $64[73.6 \%]$ & $23[26.4 \%]$ & \\
\hline
\end{tabular}

*Significant difference [p value <005]. ${ }^{* *}$ Percentages are taken from the row

NB. The same pattern of frequency and significance was observed when comparing women with low level of stress against those with high level only.

Table 4: Univariate Analysis of Possible Stressful Factors Associated with Perceived Stress Level

\begin{tabular}{|c|c|c|c|c|c|}
\hline \multirow{2}{*}{\multicolumn{2}{|c|}{$\begin{array}{l}\text { Stressful factors [Changes in the family } \\
\text { Relationship and social life] }\end{array}$}} & \multicolumn{2}{|c|}{ PSS levels } & \multirow{6}{*}{$\begin{array}{c}\text { Odds ration } \\
\text { [Cl] } \\
2.18 \\
{[0.76-6.73]}\end{array}$} & \multirow[t]{2}{*}{$P$ value } \\
\hline & & \multirow{2}{*}{$\begin{array}{c}\text { Moderate/High [n=210] } \\
28[13.3 \%]\end{array}$} & \multirow{2}{*}{$\begin{array}{c}\text { Low }[\mathrm{n}=76] \\
5[6.5 \%]\end{array}$} & & \\
\hline \multirow{4}{*}{$\begin{array}{l}* * * \text { getting support } \\
\text { from the husband }\end{array}$} & Decreased & & & & \multirow[t]{4}{*}{0.11} \\
\hline & Increased & $35[16.7 \%]$ & $20[26.3 \%]$ & & \\
\hline & Same as before & $92[43.8 \%]$ & $35[46.1 \%]$ & & \\
\hline & a Irrelevant & $55[26.2 \%]$ & $16[21.1 \%]$ & & \\
\hline \multirow{3}{*}{$\begin{array}{l}{ }^{* *} \text { Getting support } \\
\text { from family } \\
\text { members }\end{array}$} & Decreased & $23[11.0 \%]$ & $8[10.6 \%]$ & \multirow{3}{*}{$\begin{array}{c}1.05 \\
{[0.42-2.68]}\end{array}$} & \multirow[t]{3}{*}{0.918} \\
\hline & Increased & $43[20.5 \%]$ & $28[36.8 \%]$ & & \\
\hline & Same as before & $144[68.5 \%]$ & $40[52.6 \%]$ & & \\
\hline \multirow{3}{*}{$\begin{array}{l}{ }^{* *} \text { Family conflicts due to } \\
\text { the presence of all family } \\
\text { members at home most of time }\end{array}$} & Never/almost never & $66[31.4 \%]$ & $35[46.1 \%]$ & \multirow{3}{*}{$\begin{array}{c}1.86 \\
{[1.05-3.30]}\end{array}$} & \multirow[t]{3}{*}{$0.022^{*}$} \\
\hline & Sometimes & $98[46.7 \%]$ & $34[44.7 \%]$ & & \\
\hline & Always & $46[21.9 \%]$ & $7[9.2 \%]$ & & \\
\hline \multirow{3}{*}{$\begin{array}{l}{ }^{* *} \text { Conflicts between mother } \\
\text { and her children }\end{array}$} & Never/almost never & $70[33.3 \%]$ & $47[61.8 \%]$ & \multirow{3}{*}{$\begin{array}{c}3.24 \\
{[1.82-5.80]}\end{array}$} & \multirow[t]{3}{*}{$<0.001^{*}$} \\
\hline & Sometimes & $88[41.9 \%]$ & $24[31.6 \%]$ & & \\
\hline & Always & $52[24.8 \%]$ & $5[6.6 \%]$ & & \\
\hline \multirow{3}{*}{$\begin{array}{l}{ }^{* *} \text { Disruptions of social } \\
\text { communication with friends } \\
\text { and families }\end{array}$} & Never/almost never & $40[19.0 \%]$ & $40[52.6 \%]$ & \multirow{3}{*}{$\begin{array}{c}4.72 \\
{[2.58-8.67]}\end{array}$} & \multirow[t]{3}{*}{$<0.001^{*}$} \\
\hline & Sometimes & $98[46.7 \%]$ & $28[36.8 \%]$ & & \\
\hline & Always & $72[34.3 \%]$ & $8[10.6 \%]$ & & \\
\hline \multirow{3}{*}{$\begin{array}{l}{ }^{* *} \text { Feels stress due to inability } \\
\text { to share in social gatherings } \\
\text { due to lockdown }\end{array}$} & Never/almost never & $52[24.8 \%]$ & $36[47.4 \%]$ & \multirow{3}{*}{$\begin{array}{c}2.73 \\
{[1.52-4.91]}\end{array}$} & \multirow[t]{3}{*}{$<0.001^{*}$} \\
\hline & Sometimes & $78[37.1 \%]$ & $24[31.6 \%]$ & & \\
\hline & Always & $80[38.1 \%]$ & $16[21.0 \%]$ & & \\
\hline \multirow{3}{*}{$\begin{array}{l}{ }^{* *} \text { Restriction on going } \\
\text { outdoors as a result } \\
\text { of lockdown }\end{array}$} & Never/almost never & $48[22.9 \%]$ & $42[55.3 \%]$ & \multirow{3}{*}{$\begin{array}{c}4.17 \\
{[2.31-7.55]}\end{array}$} & \multirow[t]{3}{*}{$<0.001^{*}$} \\
\hline & Sometimes & $94[44.8 \%]$ & $25[32.9 \%]$ & & \\
\hline & Always & $68[32.3 \%]$ & $9[11.8 \%]$ & & \\
\hline \multirow{3}{*}{$\begin{array}{l}{ }^{* *} \text { Restriction on } \\
\text { recreational outdoor } \\
\text { activities }\end{array}$} & Never/almost never & $50[23.8 \%]$ & $28[36.8 \%]$ & 1.87 & $0.028^{*}$ \\
\hline & Sometimes & $79[37.6 \%]$ & $36[47.4 \%]$ & {$[1.02-3.41]$} & \\
\hline & Always & $81[38.6 \%]$ & $12[15.8 \%]$ & & \\
\hline${ }^{* *}$ Facing financial & Never/almost never & $74[35.2 \%]$ & $42[55.3 \%]$ & 2.27 & $0.002^{*}$ \\
\hline strain /hardships & Sometimes & $80[38.1 \%]$ & $25[32.9 \%]$ & {$[1.29-4.01]$} & \\
\hline & Always & $56[26.7 \%]$ & $9[11.8 \%]$ & & \\
\hline${ }^{* *}$ Getting basic needs for & Never/almost never & $108[51.4 \%]$ & $61[80.3 \%]$ & 3.84 & $<0.001^{*}$ \\
\hline health and safety are unmet & Sometimes & $78[37.1 \%]$ & $11[14.5 \%]$ & {$[1.98-7.56]$} & \\
\hline & Always & $24[11.5 \%]$ & $4[5.2 \%]$ & & \\
\hline **Higher workload & Never/almost never & $71[33.8 \%]$ & $42[55.3 \%]$ & & $<0.001^{*}$ \\
\hline due to COVID-19 & Sometimes & $81[38.5 \%]$ & $26[34.2 \%]$ & {$[1.37-4.28]$} & \\
\hline & Always & $58[26.7 \%]$ & $8[10.5 \%]$ & & \\
\hline ***Sleeping hours & Decreased & $70[33.3 \%]$ & $14[18.4 \%]$ & 2.21 & $0.014^{*}$ \\
\hline & Increased & $62[29.5 \%]$ & $18[23.7 \%]$ & [1.11- 4.46] & \\
\hline & Same as before & $78[37.2 \%]$ & $44[57.9 \%]$ & & \\
\hline
\end{tabular}

a not married or do not have children. *Significant difference [p value $<0.05] .{ }^{* *}$ Binary variables were constructed by combining those who answered 'always/ sometimes, [which refer to 'yes' versus never/ almost never or irrelevant which refer to ' No' as a reference. *** reference group constructed by combining those who answered 'increased/same as before 


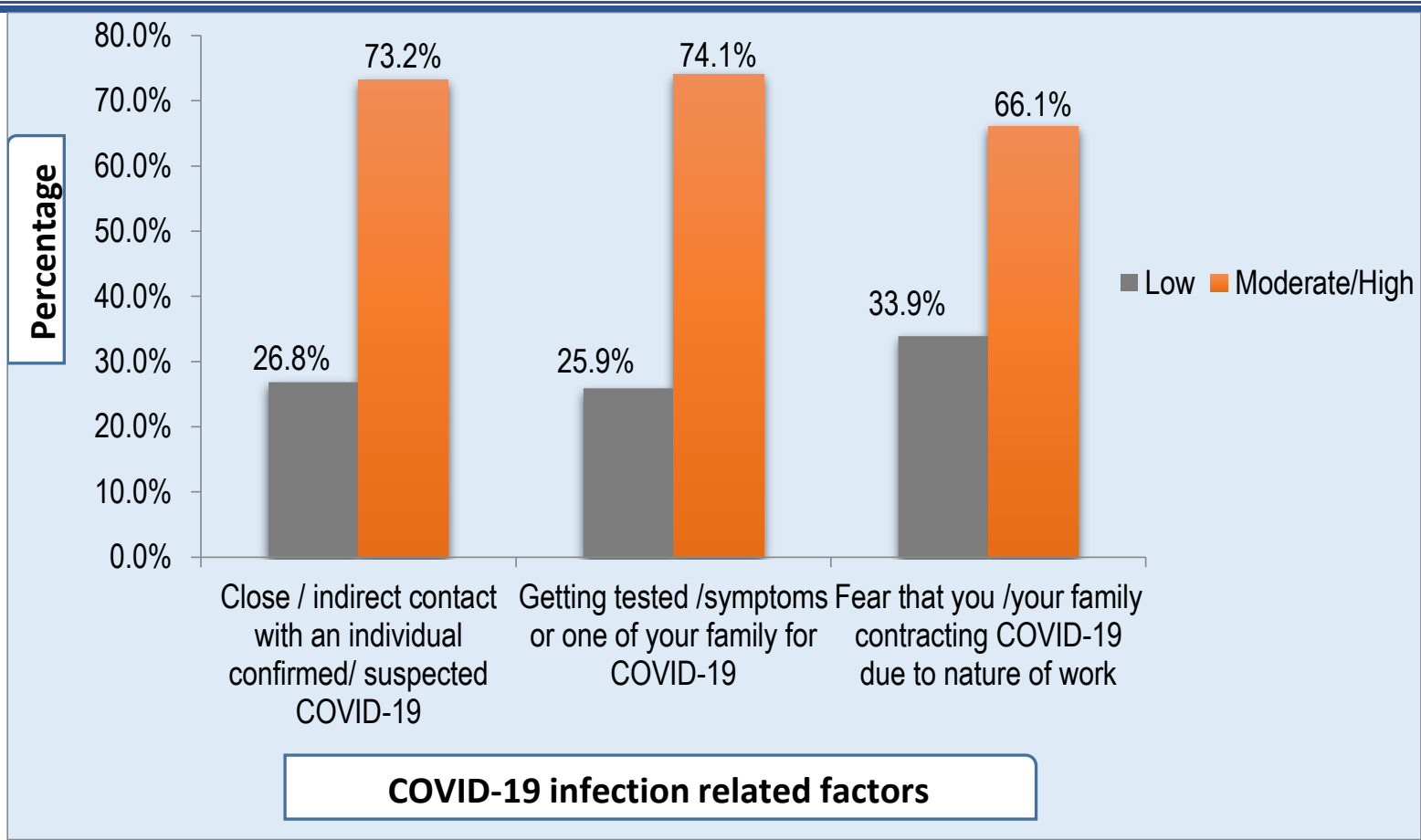

Figure 1a: COVID-19 infection related factors among females with negative response

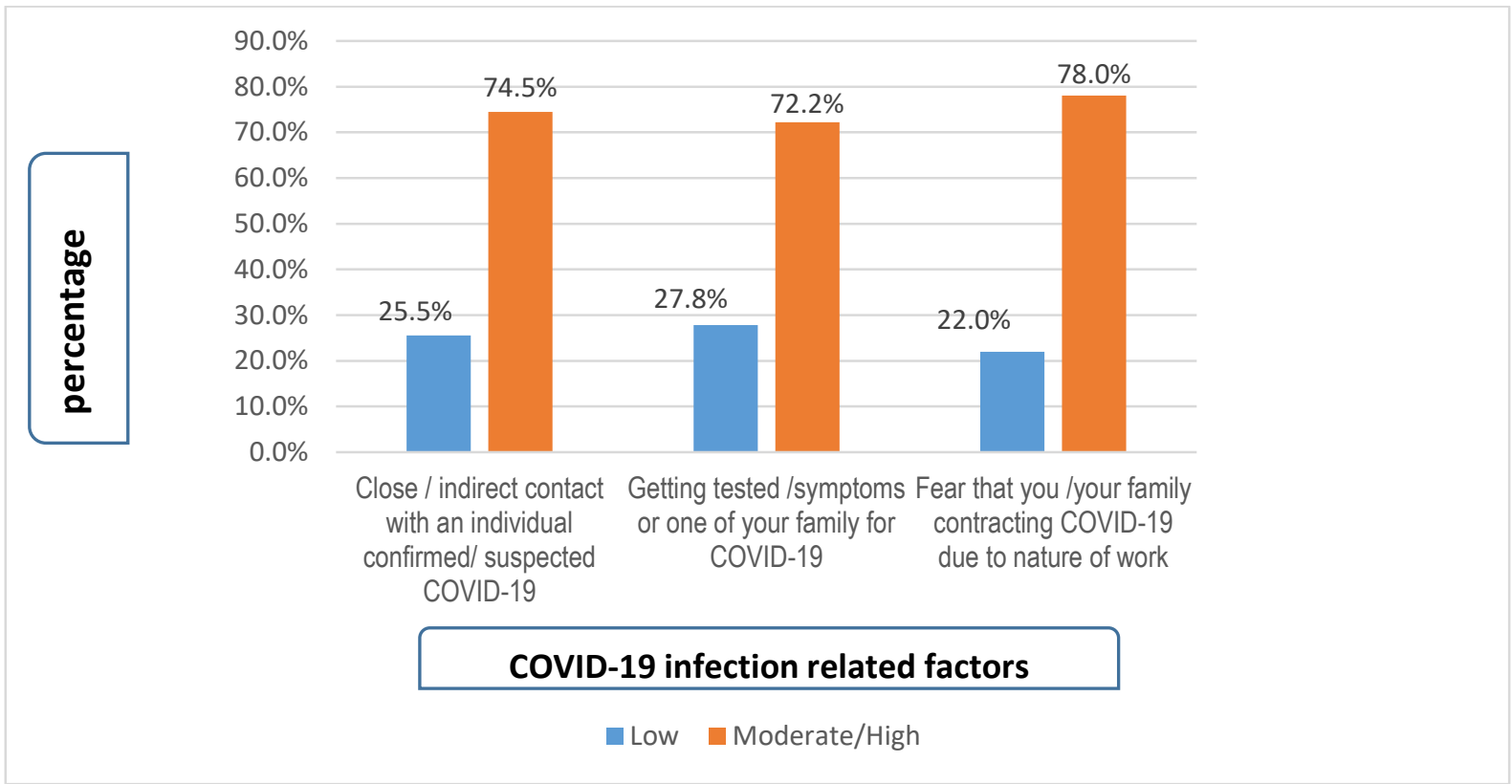

Figure 1b: COVID-19 infection related factors among females with positive response.

Table 5: Logistic Regression Analysis of Significant Factors Affecting Perceived Stress Level.

\begin{tabular}{|l|l|l|l|l|l|}
\hline $\begin{array}{l}\text { factors affecting perceived stress levels } \\
\text { [moderate or severe/mild] }\end{array}$ & $\beta$ coefficient & S.E. & Wald & Sig. & Exp [B] \\
\hline - Conflicts between mother and her children represented as a load [always and sometimes responses] & -0.73 & 0.311 & 5.558 & $0.018^{*}$ & 0.480 \\
\hline - Disruptions of social communication with friends and families [always and sometimes responses] & -1.20 & 0.312 & 14.957 & $0.000^{*}$ & 0.300 \\
\hline Getting basic needs for health and safety are unmet [always and sometimes responses] & -0.78 & 0.356 & 4.893 & $0.027^{*}$ & 0.455 \\
\hline Feel stressed due to inability for social gatherings [always and sometimes responses] & -0.66 & 0.314 & 4.530 & $0.033^{*}$ & 0.513 \\
\hline Age[< 50years] & -0.67 & 0.342 & 3.917 & $0.048^{*}$ & 0.508 \\
\hline Constant & 7.10 & 1.074 & 43.722 & 0.000 & $1.213 \mathrm{E} 3$ \\
\hline
\end{tabular}

*significantly influencing factor [p-value $<0.05$ ] 


\section{DISCUSSION}

Corona virus disease pandemic emerged in late 2019 in Wuhan, China; and had spread universally by the start of the year 2020 [11].

Literature review on the psychological impact of quarantine during past epidemics and pandemics [e.g., SARS, H1N1, Ebola, MERS, equine influenza] concluded that the quarantined persons are more likely to show psychological distress versus non-quarantined ones [12]. Also, high prevalence of psychological symptomatology, as post-traumatic and depressive symptoms, stress, and anxiety among quarantined persons has been noticed [13].

Recent evidence on the impact of COVID-19 proposes that women's life will be affected disproportionately as women take on more care demands at home. Globally, women earn less, save less, and have less access to social protections. Such risks limit women's ability to support themselves and their families, especially for households headed by females [14].

For the first time, this study aimed to detect the perceived stress by Egyptian educated females during COVID-19 lockdown. The study included 286 Egyptian females with mean age 46.5 years old, most of them were married and living with their husbands [75.3\%] in urban areas [93.7\%].

In Egypt, a partial lockdown was applied as it was only for few hours every day however, the overall PSS in participants reflecting a stressful impact as nearly three quarters of females were experiencing different levels of stress related to covid-19 either moderate [68.5\%] or high [4.9\%]. Similarly, Tabassum et al. in Bangladesh ${ }^{[14]}$ found that $81 \%$ of participants had various levels of stress during covid-19 pandemic. Wang et al. in China ${ }^{[15]}$ revealed that $8.1 \%$ were having moderate to severe levels of stress. Likewise, Qiu et al. ${ }^{[5]}$ recorded that almost $35 \%$ of their study participants showed psychological distress. Also, in consistence with a national wide survey in Italy on a sample of 2766 participants and most of them were females: 1982 [71.7\%] that aimed to assess the psychological distress during the COVID-19 pandemic by using Depression, Anxiety and Stress Scale-21 items [DASS-21]. The survey revealed that $72.8 \%$ of the respondents showed average range of stress, $14.6 \%$ experienced high range of stress, and only $12.6 \%$ were of extremely high range of stress ${ }^{[16]}$. This also agrees with the first systematic review and metaanalysis carried out to assess the prevalence of stress, anxiety and depression in the general population after COVID-19 pandemic. The prevalence of stress in 5 studies with a total sample size of 9074 was found to be $29.6 \%$ [ $95 \%$ confidence limit: 24.3-35.4] [17]. The discrepancy in prevalence may be explained by the variety of symptoms found by each research instrument and the epidemic context ${ }^{[18]}$.

On the contrary, Zhang and $\mathrm{Ma}{ }^{[19]}$, in China detected mild stressful impact that may be due to that their study was conducted when the disease outbreak was not considered as severe. Additionally, it is possible that participants still might not have been properly informed about the severity of the virus.

Our socio-demographic data suggest that being under 50 years old was a risk factor for perceived stress as younger females below 50 years suffered a significant greater levels of stress than those older than 50 . This finding was in agreement with other studies that revealed high psychosocial stress to be more common among young

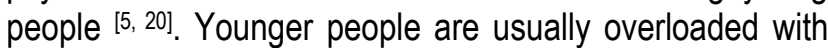
domestic, social, and work commitments that make them prone more to psychological stress. However, other researches ${ }^{[21,22]}$ concluded that older people suffer higher levels of stress and the highest levels were attained at 5565 years of age. This controversy may due to the difference in culture of the study population where older age may suffer from lack of social networks that could alleviate perceived stress in such situation [23].

Additionally, the present study revealed that none of other demographic variables significantly predicted the perceived stress score in the multiple regression analysis. It is noteworthy that working females experienced significant moderate to higher level of stress versus non-working ones. In accordance, Nayar et al. ${ }^{[24]}$ stated that occupations were found to be predictors of anxiety and stress.

Agricultural work in rural areas grants population more psychological protection however, it is surprising in this study, those who settled in rural areas reported nonsignificant higher rate of stress than who were from urban or suburban area which supported by others ${ }^{225]}$. Perhaps in the rural community, the lack of access to public services, worse healthcare provision against the pandemic and lack of transportation means to keep contact with beloved ones increase the perception of isolation and the vulnerability of being stressed.

According to the current results, people who were married demonstrated non-significant lower levels of stress than those who were unmarried, either single, widowed, separated or divorced, which was in agreement with Rodríguez et al. ${ }^{[25]}$ who stated that having a partner or someone with whom to share the experience and have 
frequent contact with, tend to be of lower stress levels due to confinement than single or unmarried one.

This study also found that the educational level of females insignificantly associated with the stress level which supported the finding of Rodriguez et al. ${ }^{[25]}$ who found people with higher levels of education exhibited lower levels of anxiety and stress and better control of the stress than those with lower levels of education. Higher educational level is usually accompanied with better knowledge and attitude toward protection and management of such situations.

The present study documented that most of the participants had positive stressful COVID-19-related lifestyle changes. As recreational outdoor activities were discontinued and social gathering and communication also experiencing other stressful events like relationship or housing problems, working load, and financial problems, or fear of the inability of obtaining basic needs due to lockdown measures.

These results are consistent with Brooks et al. [11], who noted that difficulties obtaining basic supplies and protective equipment, as well as gaining access to information and resources, can increase stress levels in isolation and, as a result, exacerbate how stress is handled during confinement. People were also exhausted as a result of the longer quarantine period, as well as concerns of contamination and insufficient supplies, insufficient information, financial loss, and stigma, all of which can lead to depression and a high level of perceived stress ${ }^{[11,12]}$.

Similarly, an early study on COVID-19 mental health outcomes in China on 1210 respondents found higher levels of perceived stress with a positive correlation with female gender, indicating that women could be at increased risk for mental disorders ${ }^{[15]}$.In addition, previous epidemiological studies have shown that women are more susceptible to depression and stress [26].

Women are vulnerable to stress because they are exposed to life stressors. It is normal for women to serve their families, especially during times of lockdown, by handling household chores and office work at home. They must continually meet the needs of all family members, such as food and cleaning, as well as home-schooling children who are unable to receive a formal education due to the circumstances. As a result, females become physically and mentally exhausted [27].

A change in the amount of time spent outside may also affect the schedule at home, such as the time of waking and sleeping, as well as the time of a meal. Many people can experience increased fatigue as a result of the increased mental workload induced by covid-19, and this fatigue may also be caused by psychological factors like stress [27]. In a tragedy, a rise in financial and family stress may be linked to certain avoidance habits, worsening their mental health and leading to a more inactive lifestyle. [27].

Even though decrease in social support was the least stressful factor in the current study, since almost all participants had better or even unchanged husband and family support, women often had disputes with their children or other family members because they were at home most of the time, which increased their stress. In accordance, Lau et al. ${ }^{[28]}$ stated that family and friends were highly regarded in times of crisis because family members were more likely to spend time together while they thought about and avoided going to public places. Friends were giving each other heartfelt greetings.

Sleep disruption was identified as a stressful event in the current study, with either a decrease [29.3\%] or an increase [28.0\%]. That can be explained by Niles and O'Donovan [29], who stated that the pandemic left people feeling confused and unsure, as well as fearful. All of these emotions will contribute to poor sleep quality. Furthermore, the disturbance of everyday life as well as the uncertain nature of disease may be the reasons behind the high prevalence of stress among Egyptian females because it is the first experience of this type of lockdown.

\section{Conclusions:}

It is known that the research is original, but it is also preliminary. However, the COVID-19 pandemic is a unique experience that has left a lasting impression on females.

The average of the total score of perceived stress during the quarantine period was 17.1 \pm 5.37 [moderate selfperceived stress level]. Significant associations were found between stress, and being younger and working. Other socio-demographic variables including educational level, residence, and marital status were insignificantly associated with perceived stress level. It may be also understandable that disruptions of social communication with friends and families, "getting basic needs for health and safety are unmet" then, conflicts between mother and her children represented as a load", being younger women [below 50 years], and "feel stressed due to inability for social gatherings" were the greatest explanatory potential for perceived stress in females confined due to COVID-19.

The negative psychological health consequences of "stay-at-home" measures on women highlight the importance of addressing the gender impacts of this 
pandemic and take these impacts into consideration when designing policies to slow the spread of the pandemic. Also, continuous monitoring of consequences should become routine as part of preparedness efforts against pandemic.

Furthermore, this study suggests that mental health providers offer phone-based or web-based therapeutic assistance to their users when required, as well as daily phone-based or web-based follow-up to all of their users to mitigate the impact of the pandemic on pre-existing mental illnesses and avoid relapse.

This strategy could make mental health services more accessible, particularly in periods of social isolation. It's worth noting that this can only be done if public and/or private women's organizations work together at the heart of the COVID-19 response to provide the appropriate equipment and services to reach all levels. Continuous monitoring of consequences should become routine as part of preparedness efforts against pandemic.

Designing plans with a deliberate emphasis on the lives and futures of women and girls would profoundly drive better and more sustainable development results for all, enable a faster recovery, and put us back on track to meet the Sustainable Development Goals.

\section{Limitations:}

Due to the lockdown and "stay at home measures" to control the epidemic, we created a Google questionnaire and gathered data through social media channels that were only used by women who were able to participate. Consequently, randomization technique was not followed and a relatively small sample was recruited and the findings of this study should be cautiously interpreted. The restriction of the sample and the non- random method of data collection prevent the findings from being generalized to a larger population. Previous mental and psychological status of participants could not be assessed before the outbreak so we cannot exclude preexisting effect. In addition, possible exposure to COVID-19 cases or close contacts could exaggerate their responses. Possibility of residual confounding caused by unmeasured covariates can't be excluded.

\section{$\underline{\text { Declarations }}$}

\section{Consent for publication: Not applicable}

Availability of data and material: Upon reasonable request, the corresponding author will provide all data produced or analyzed during this report.

\section{Competing interests}

There are no conflicting interests declared by the authors.

Funding: The authors declare that no funding persons were involved in sponsoring or funding this study, no grants were taken, and the study was conducted on the expense of the authors.

\section{Acknowledgment}

The researchers would like to express their gratitude to the EMWA Board and members for their support to conduct this research and design its questionnaire through validated scientific methods. Also, the researcher appreciated the valuable recommendations and the scientific advices from both professors, Mervat Elrafie, Professor of Public Health and Community Medicine, Cairo University and Thoryah Ahmed Abdelfattah, Professor of Public Health and Community Medicine, Al-Azhar University [Egypt].

\section{REFERENCES}

1. Torales J, O'Higgins M, Castaldelli-Maia JM, Ventriglio A. The outbreak of COVID-19 coronavirus and its impact on global mental health. Int J Soc Psychiatry. 2020 Jun; 66[4]:317-320. [DOI: 10.1177/0020764020915212].

2. Adams-Prassl A, Boneva T, Golin M, Rauh C. The impact of the coronavirus lockdown on mental health: evidence from the US. Human Capital and Economic Opportunity Working Group. Cambridge Working Papers in Economics: 2037. 2020: 1-20; 2020.

3. World Health Organization [WHO]. A year without precedent: WHO's COVID-19 response [2020]. Available at: https://www.who.int/news-room/spotlight/a-year-withoutprecedent-who-s-covid-19-response

4. Rossi R, Socci V, Talevi D, Mensi S, Niolu C, Pacitti F, Di et al. COVID-19 Pandemic and Lockdown Measures Impact on Mental Health Among the General Population in Italy. Front Psychiatry. 2020; 11:790. [DOI: 10.3389/fpsyt.2020. 00790].

5. Qiu J, Shen B, Zhao M, Wang Z, Xie B, Xu Y. A nationwide survey of psychological distress among Chinese people in the COVID-19 epidemic: implications and policy recommendations. Gen Psychiatr. 2020 Mar 6; 33[2]: e100213. [DOI: 10.1136/gpsych-2020-100213].

6. Dong L, Bouey J. Public Mental Health Crisis during COVID19 Pandemic, China. Emerg Infect Dis. 2020 Jul; 26[7]:16161618. [DOI: 10.3201/eid2607.200407].

7. Thomas KA, Clifford S. Validity and Mechanical Turk: An assessment of exclusion methods and interactive experiments. Comp Human Behavior. 2017 Dec 1; 77:184-97. [DOI: /10.1016/j. chb.2017.08.038].

8. Cohen $\mathrm{S}$, Kamarck T, Mermelstein R. A global measure of perceived stress. J Health Soc Behav. 1983 Dec; 24[4]:38596. [PMID: 6668417].

9. Ghassan S, and Mashael F. Perceived stress and anxiety among sample of post graduate educational rehabilitation students in faculty of education, Tishreen University. J Res Sci Stud Arts Humanit. 2014; 36:255-77. 
10. Khalili R, Sirati Nir M, Ebadi A, Tavallai A, Habibi M. Validity and reliability of the Cohen 10-item Perceived Stress Scale in patients with chronic headache: Persian version. Asian J Psychiatr. 2017 Apr; 26:136-140. [DOI: 10.1016/j.ajp. 2017.01.010].

11. Brooks SK, Webster RK, Smith LE, Woodland L, Wessely S, Greenberg N, Rubin GJ. The psychological impact of quarantine and how to reduce it: rapid review of the evidence. Lancet. 2020 Mar 14; 395[10227]:912-920. [DOI: 10.1016/ S0140-6736[20]30460-8].

12. Jeong $H$, Yim HW, Song YJ, Ki M, Min JA, Cho J, Chae JH. Mental health status of people isolated due to Middle East Respiratory Syndrome. Epidemiol Health. 2016 Nov 5; 38:e2016048. [DOI: 10.4178/epih.e2016048].

13. Power K. The COVID-19 pandemic has increased the care burden of women and families. Sustainability: Science, Practice and Policy. 2020; 16[1]:67-73. [DOI: 10.1080/ 15487733.2020. 1776561].

14. Tabassum M, Parvej MI, Ahmed F, Zafreen F, Sultana S. Effect of COVID-19 on perceived stress among Bangladeshi people. Mental Health Rev J. 2021; 26[2]:143-151. [DOI: 10.1108/MHRJ-07-2020-0042].

15. Wang C, Pan R, Wan X, Tan Y, Xu L, Ho CS, Ho RC. Immediate Psychological Responses and Associated Factors during the Initial Stage of the 2019 Coronavirus Disease [COVID-19] Epidemic among the General Population in China. Int J Environ Res Public Health. 2020 Mar 6; 17[5]:1729. [DOI: 10.3390/ijerph17051729].

16. Mazza C, Ricci E, Biondi S, Colasanti M, Ferracuti S, Napoli C, Roma P. A Nationwide Survey of Psychological Distress among Italian People during the COVID-19 Pandemic: Immediate Psychological Responses and Associated Factors. Int J Environ Res Public Health. 2020 May 2; 17[9]:3165. [DOI: 10.3390/ijerph17093165].

17. Salari N, Hosseinian-Far A, Jalali R, Vaisi-Raygani A, Rasoulpoor S, Mohammadi M, Rasoulpoor S, Khaledi-Paveh B. Prevalence of stress, anxiety, depression among the general population during the COVID-19 pandemic: a systematic review and meta-analysis. Global Health. $2020 \mathrm{Jul}$ 6; 16[1]:57. [DOI: 10.1186/s12992-020-00589-w].

18. Cooch EG, Conn PB, Ellner SP, Dobson AP, Pollock KH. Disease dynamics in wild populations: modeling and estimation: a review. J Ornithol. 2012; 152:485-509. [DOI: 10.1007/s10336-010-0636-3].

19. Zhang Y, Ma ZF. Impact of the COVID-19 Pandemic on Mental Health and Quality of Life among Local Residents in Liaoning Province, China: A Cross-Sectional Study. Int J Environ Res Public Health. 2020 Mar 31; 17[7]:2381. [DOI: 10.3390/ijerph17072381].

20. Kessler RC, Andrews G, Colpe LJ, Hiripi E, Mroczek DK, Normand SL, Walters EE, Zaslavsky AM. Short screening scales to monitor population prevalence and trends in nonspecific psychological distress. Psychol Med. 2002 Aug; 32[6]:959-76. [DOI: 10.1017/s0033291702006074].
21. Ramos G. Women at the core of the fight against COVID-19 crisis. Organization for Economic Cooperation and Development [OECD]. Policy Responses to Coronavirus [COVID-19]. 2020. Available online: https://www.oecd. org/coronavirus/policy-responses/women-at-the-core-of-thefight-against-covid-19-crisis-553a8269/ [accessed on 15 June 2020].

22. Balanzá-Martínez $V$, Kapczinski $F$, de Azevedo Cardoso $T$, Atienza-Carbonell B, Rosa AR, Mota JC, De Boni RB. The assessment of lifestyle changes during the COVID-19 pandemic using a multidimensional scale. Rev Psiquiatr Salud Ment [Engl Ed]. 2021; 14[1]:16-26. [DOI: 10.1016/j.rpsm. 2020.07.003].

23. Reinecke L, Aufenanger S, Beutel ME, Dreier M, Quiring O, Stark B, Wölfling K, Müller KW. Digital stress over the life span: The effects of communication load and internet multitasking on perceived stress and psychological health impairments in a German probability sample. Media Psychology. 2017; 20[1]:90-115. [DOI: 10.1080/15213269. 2015. 1121832]

24. Nayar LJ, Kansara Y, and Ahmad S. "100 Million and More Indian Jobs Are At Risk after COVID-19 Lockdown. Is Your Job Safe?" Outlook India, Apr-2020. Available at: https://magazine.outlookindia.com/story/business-news-100million-and-more-indian-jobs-are-at-risk-after-covid-19lockdown-is-your-job-safe/303094. [Accessed: December2020].

25. Rodríguez S, Valle A, Piñeiro I, Rodríguez-Llorente $C$, Guerrero E, Martins L. Socio-demographic Characteristics and Stress of People from Spain Confined by COVID-19. Eur J Invest Health Psychol Education. 2020; 10[4]:1095-105. [DOI: 10.3390/ejihpe10040077].

26. Remes $\mathrm{O}$. "Women are far more anxious than men - here's the science," The Conversation, [2016]. [Online]. Available at: https://theconversation.com/women-are-farmore-anxiousthan-men-heres-the-science-60458. [Accessed: 18-Apr2020].

27. Ahmad A, Rahman I, Agarwal M. Factors Influencing Mental Health during Covid-19 Outbreak: An Exploratory Survey among Indian Population. Journal of Health Sciences 2020; 10[2]:147-156. [DOI: 10.17532/jhsci.2020.950].

28. Lau JT, Yang X, Tsui HY, Kim JH. Impacts of SARS on healthseeking behaviors in general population in Hong Kong. Prev Med. 2005; 41[2]:454-62. [DOI: 10.1016/j.ypmed.2004. 11.023].

29. Niles AN, O'Donovan A. Comparing anxiety and depression to obesity and smoking as predictors of major medical illnesses and somatic symptoms. Health Psychol. 2019 Feb; 38[2]:172181. [DOI: 10.1037/hea0000707]. 

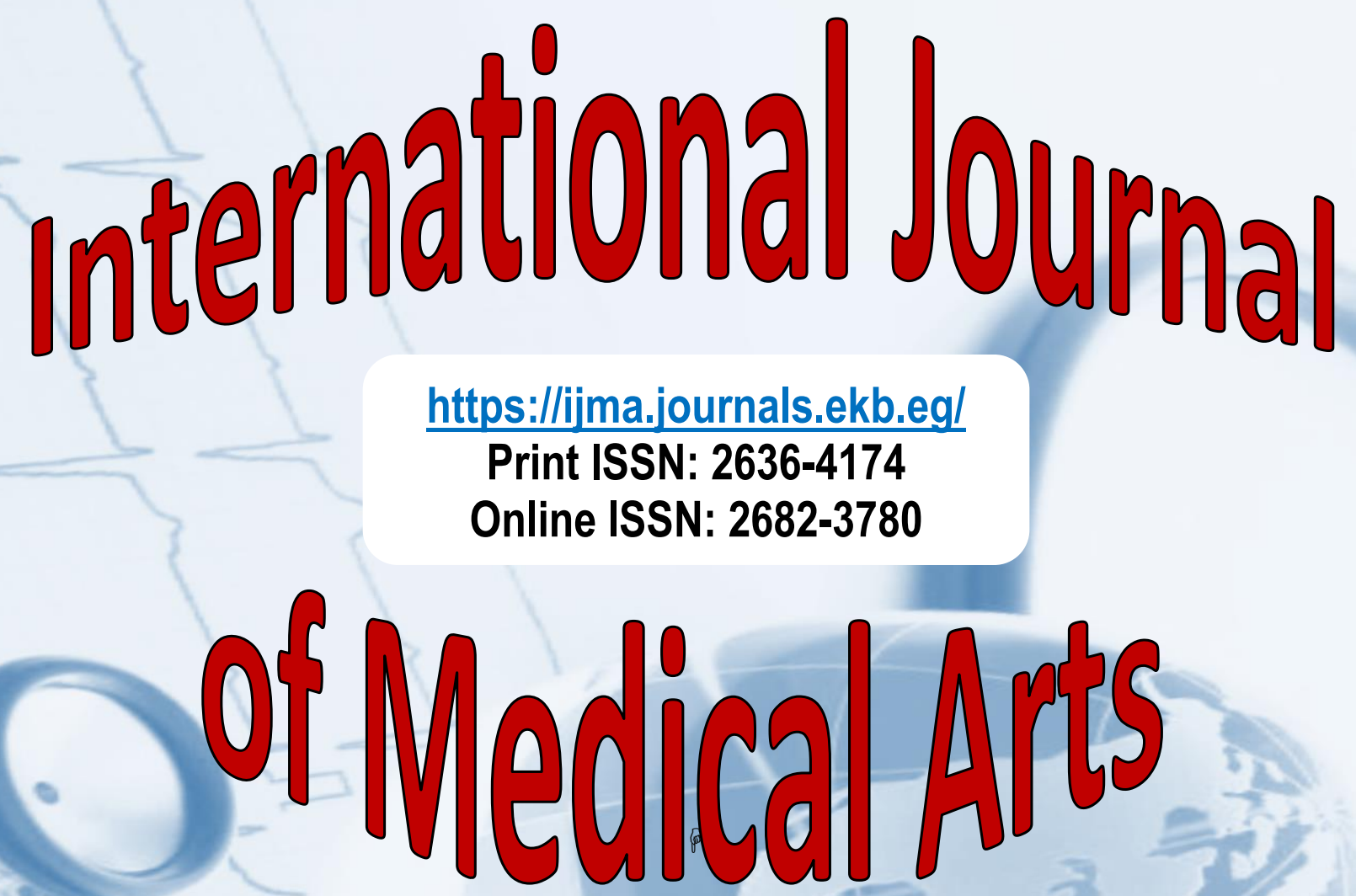